\title{
Six-minute walking test in children with ESRD: discrimination validity and construct validity
}

\author{
Tim Takken • Raoul Engelbert • Monique van Bergen • \\ Jaap Groothoff • Jeroen Nauta • Koen van Hoeck • \\ Marc Lilien • Paul Helders
}

Received: 5 March 2009 /Revised: 25 May 2009 /Accepted: 15 June 2009 /Published online: 25 July 2009

(C) The Author(s) 2009. This article is published with open access at Springerlink.com

\begin{abstract}
The six-minute walking test (6MWT) may be a practical test for the evaluation functional exercise capacity in children with end-stage renal disease (ESRD). The aim of this study was to investigate the 6MWT performance in children with ESRD compared to reference values obtained in healthy children and, secondly, to study the relationship between 6MWT performance with anthropometric varia-
\end{abstract}

T. Takken $(\varangle) \cdot$ R. Engelbert $\cdot$ M. van Bergen $\cdot$ P. Helders Department of Pediatric Physical Therapy \& Exercise Physiology, Wilhelmina Children's Hospital,

University Medical Centre Utrecht,

Room KB.02.056, P.O. Box 85090, 3508 AB Utrecht,

The Netherlands

e-mail: t.takken@umcutrecht.nl

R. Engelbert

University of Applied Sciences Amsterdam,

Hogeschool van Amsterdam, Education of Physical Therapy,

Amsterdam, The Netherlands

J. Groothoff

Department of Pediatric Nephrology, Emma Children's Hospital, Academic Medical Centre,

Amsterdam, The Netherlands

J. Nauta

Department of Pediatric Nephrology, Sophia's Children Hospital, Erasmus Medical Centre,

Rotterdam, The Netherlands

K. van Hoeck

Department of Pediatric Nephrology,

University Hospital Antwerp,

Antwerp, Belgium

\section{Lilien}

Department of Pediatric Nephrology,

Wilhelmina Children's Hospital,

University Medical Centre Utrecht,

Utrecht, The Netherlands bles, clinical parameters, aerobic capacity and muscle strength. Twenty patients (13 boys and seven girls; mean age $14.1 \pm 3.4$ years) on dialysis participated in this study. Anthropometrics were taken in a standardized manner. The 6MWT was performed in a 20-m-long track in a straight hallway. Aerobic fitness was measured using a cycle ergometer test to determine peak oxygen uptake $\left(\mathrm{V}_{2 \text { peak }}\right)$, peak rate $\left(\mathrm{W}_{\text {peak }}\right)$ and ventilatory threshold (VT). Muscle strength was measured using hand-held myometry. Children with ESRD showed a reduced 6MWT performance ( $83 \%$ of predicted, $p<0.0001$ ), irrespective of the reference values used. The strongest predictors of 6MWT performance were haematocrit and height. Regression models explained 59\% (haematocrit and height) to $60 \%$ (haematocrit) of the variance in 6MWT performance. 6MWT performance was not associated with $\mathrm{V}_{2 \text { peak }}$, strength, or other anthropometric variables, but it was significantly associated with haematocrit and height. Children with ESRD scored lower on the 6MWT than healthy children. Based on these results, the 6MWT may be a useful instrument for monitoring clinical status in children with ESRD, however it cannot substitute for other fitness tests, such as a progressive exercise test to measure $\mathrm{VO}_{2 \text { peak }}$ or muscle strength tests.

Keywords Exercise capacity · Kidney disease . Muscle strength $\cdot$ Physical activity

\section{Introduction}

Children with end-stage renal disease (ESRD) are characterized by multiple factors that influence their exercise capacity, such as anaemia, metabolic acidosis, electrolyte imbalance, osteopaenia, growth failure, undernutrition, 
fluid imbalance, muscle wasting and a sedentary life style $[1,2]$.

In recent years exercise training has attracted interest as a potential means to improve the stamina, endurance and physical activity capacity of children and adults with ESRD [3-5]. A practical test for the evaluation of the physical activity capacity or functional exercise capacity of patients with ESRD might be the six-minute walking test (6MWT) $[4,6]$.

The 6MWT is a self-paced, submaximal exercise test used to assess functional exercise capacity in children with chronic diseases. It has been widely used in adults, most extensively in patients with cardiopulmonary diseases, and is currently the test of choice when a functional walk test is required for clinical or research purposes [7]. The test is well-standardized and easy to administer. The 6MWT is increasingly being utilized in paediatric populations [8-10] and has been found to be a valid estimate of physical fitness in, for example, children with severe cardiopulmonary disease, cystic fibrosis (CF) and juvenile idiopathic arthritis (JIA) [11-13]. The test has shown good reliability [14, 15] and is frequently employed to assess the response to interventions [4, 16, 17]. However, there are some limitations to this test; for example, it is unclear how hard the patient is working and how its score is related to other objective measures of exercise capacity in children with chronic conditions like ESRD.

Reference values and prediction equations from healthy children have recently been published, making it possible to determine the predicted 6MWD for individual patients [1820]. Age, height, weight and gender are known to independently predict $6 \mathrm{MWD}$ in healthy adults [21]. In children, varying associations have been reported between anthropometric variables, fitness variables and 6MWD [11, $13-15,18,19,22]$.

The aim of the study reported here was to investigate 6MWT performance in children with ESRD compared to reference values obtained in healthy children (discrimination validity) and, secondly, to study the relationship between 6MWT performance with anthropometric variables, clinical variables, aerobic fitness and muscle strength (construct validity).

\section{Patients and methods}

Patients

Dutch speaking children between 8 and 18 years of age with a diagnosis of ESRD and treated with either haemodialysis or peritoneal dialysis for more than 3 months were included. The patients had to be able to perform exercise testing without musculoskeletal problems that could limit the exercise testing, and they had to be able to understand the exercise testing procedures. The eligible patients were identified by a senior paediatric nephrologist from each centre (JG, JN, KvH, ML).

A total of 25 children fulfilled the enrollment requirements and invited to participate. The parents of five children refused to participate due to personal or logistic reasons. Informed consent was obtained from all parents and also from the children if they were older than 12 years of age. The study was approved by the Medical Ethics Committee of all participating centres.

Patients were recruited from the paediatric nephrology outpatient clinic of the Wilhelmina Children's Hospital Utrecht, Emma Children's Hospital Amsterdam, Sophia Children's Hospital Rotterdam and the University Hospital Antwerp, Belgium. All children were tested in their local hospital by the same research staff using the same mobile equipment to reduce bias (MvB, TT and RHE).

Twenty patients were included in this cross-sectional study. Eleven patients were treated with haemodialysis (mean age $14.1 \pm 3.7$ years), add nine were treated with peritoneal dialysis (mean age $14.0 \pm 3.2$ years). The medical histories of these children were obtained from respective hospital's patients' medical records. A summary of their medical history is presented in Table 1 . To eliminate any possible influence of a recent haemodialysis session on exercise capacity, patients were tested immediately prior to haemodialysis treatment or on an off-dialysis day.

\section{Methods}

\section{Clinical characteristics}

Standing height and weight were measured to the nearest centimetre and $100 \mathrm{~g}$, respectively, in a standardized method, with the patient not wearing heavy clothing and shoes. A body mass index (BMI) [weight $(\mathrm{kg}) /$ height $\left(\mathrm{m}^{2}\right)$ ] was then calculated from these values. Subcutaneous fat distribution was measured from skinfold measurements using Harpenden skinfold callipers. The measurements were taken at four sites, the triceps, biceps, subscapular and supra-iliacal [23], and converted to percentage body fat [24]. The systolic and diastolic blood pressure $(\mathrm{mmHg})$ was measured in a sitting position using an oscillometric blood pressure device (Dinamap 8100 T; Critikon, Tampa, FL). The values of height, weight, BMI and blood pressure were compared with reference values for healthy, age- and gender-matched children $[25,26]$.

\section{Six-minute walk test}

The 6MWT was performed on a $20-\mathrm{m}$ track in a straight hospital corridor. Patients were instructed to cover the 
Table 1 Medical history of the paediatric patients enrolled in the study
ACE, Angiotensin converting enzyme; rHuEPO, recombinant human erythropoietin

Data are given as mean $\pm \mathrm{SD}$ or as $n(\%)$

\begin{tabular}{ll}
\hline Characteristics & Patients $(n=20)$ \\
\hline Time on dialysis (months) & $27.5 \pm 38.2$ \\
Haemodialysis (\%) & 55 \\
Causes of renal failure & \\
Congenital structural abnormalities & 4 \\
Hereditary renal disorders & 3 \\
Glomerulonephritis & 8 \\
Systemic diseases & 3 \\
Other & 1 \\
Unknown & 1 \\
Hypertension medication & \\
ACE inhibitors & 4 \\
ACE inhibitors + calcium blockers & 1 \\
ACE inhibitors + calcium blockers + beta-blockers & 2 \\
Calcium blockers & 3 \\
Calcium blockers + beta-blockers & 2 \\
None & 8 \\
Growth hormone & 8 \\
rHuEPO & 20 \\
Presence left ventricle hypertrophy & 5 \\
\hline
\end{tabular}

largest possible distance in $6 \mathrm{~min}$ at a self-chosen walking speed. Turns were made on both ends of the 20-m track. The distance walked was recorded with a lap counter. At 1-min intervals, the patients were encouraged in a standardized way [17] and time, recorded with a stopwatch, was called. At the end of the test, the patient was asked to stand still, and the distance covered in the final partial lap was measured with measuring tape. The total distance covered was calculated by multiplying the number of laps (back and forth once) by $40 \mathrm{~m}$ and then adding the additional meters of the final partial lap. The total distance walked was rounded off to the nearest meter. The walking distance of our subjects was compared with predicted 6MWD using the gender-specific prediction equations from Geiger et al. [19] and the height-specific centile charts from Li et al. [20].

\section{Progressive exercise test}

Patients performed a progressive exercise test using an electronically braked cycle ergometer (Lode Corrival Pediatric; Lode BV, Groningen, the Netherlands). The test started with $1 \mathrm{~min}$ of unloaded cycling before the application of resistance to the ergometer. After this first minute, the work rate was increased with a constant increment of 10,15 or $20 \mathrm{~W}$ each minute based on height according to the Godfrey protocol [27]. For patients $<120 \mathrm{~cm}$, the work rate was increased by $10 \mathrm{~W} / \mathrm{min}$; patients between 120 and $150 \mathrm{~cm}$, by $15 \mathrm{~W} / \mathrm{min}$; patients $>150 \mathrm{~cm}$, by $20 \mathrm{~W} / \mathrm{min}$. This protocol continued until the patient voluntarily stopped because of exhaustion, despite strong verbal encouragement of the test-leader. During the test, subjects breathed through a facemask (Hans Rudolph, Kansas City, MO) connected to a calibrated respiratory gas analysis system (Cortex Metamax $\mathrm{B}^{3}$; Cortex Medical, Leipzig, Germany). Expired gas was passed through a flowmeter (Triple $\mathrm{V}$ volume transducer), an oxygen $\left(\mathrm{O}_{2}\right)$ analyser and a carbon dioxide $\left(\mathrm{CO}_{2}\right)$ analyser. The flowmeter and gas analysers were connected to a computer, which calculated breath-by-breath minute ventilation (VE), oxygen uptake $\left(\dot{\mathrm{VO}_{2}}\right)$, carbon dioxide output $\left(\dot{\mathrm{V}} \mathrm{CO}_{2}\right)$, and the respiratory exchange ratio $\left(\mathrm{RER} ;=\dot{\mathrm{V}} \mathrm{CO}_{2} / \mathrm{V} \mathrm{O}_{2}\right)$. The oxygen uptake eliciting the ventilatory threshold (VT) was determined by using the criteria of an increase in both the ventilatory equivalent of oxygen $\left(\dot{\mathrm{VE}} / \dot{\mathrm{V}} \mathrm{O}_{2}\right)$ and endtidal pressure of oxygen $\left(\mathrm{PETO}_{2}\right)$ with no increase in the ventilatory equivalent of carbon dioxide $\left(\dot{\mathrm{VE}} / \mathrm{V} \mathrm{CO}_{2}\right)$ [28]. Heart rate was measured continuously during the maximal exercise test by using a heart rate monitor (Polar, Kempele, Finland). Maximal effort was defined as meeting one of the two criteria: heart rate $>180$ beats per minute or RER $>1.0$. Peak work rate $\left(\mathrm{W}_{\text {peak }}\right)$ was defined as the highest work rate attained during the test.

Peak oxygen uptake $\left(\mathrm{VO}_{2 \text { peak }}\right)$ was defined as the average value for the last $30 \mathrm{~s}$ during the maximal exercise test. Relative $\mathrm{VO}_{\text {2peak }}$ was calculated as absolute $\mathrm{V} \mathrm{O}_{2 \text { peak }}$ divided by body mass. Predicted $\mathrm{V} \mathrm{O}_{2 \text { peak }}$ and $\mathrm{W}_{\text {peak }}$ values were obtained from established reference values for ageand gender matched healthy Dutch controls [29]. 


\section{Muscle Strength}

Muscle strength was measured with a hand-held dynamometer (Citec dynamometer CT 3001; C.I.T. Technics, Groningen, the Netherlands) in Newton (N). Muscle groups of the lower extremity assessed were knee flexors and extensors, hip flexors, and dorsiflexors of the ankle joint. Grip strength was also assessed as a indicator of global muscle strength. Maximum muscle strength was tested with the "break" method, in which the examiner gradually overcomes the muscle force of the patient and stops at the moment the extremity gives way.

Grip strength was measured using a Citec dynamometer equipped with an extension for measuring grip strength with the "make" method. Patients were sitting upright with the arm in shoulder adduction and at $70^{\circ}$ of flexion. The elbow was flexed $30^{\circ}$. The extension was gripped as hard as possible for $3 \mathrm{~s}$ without pressing the instrument against the body and without touching the elbow to the body. Grip strength was included as a indicator of global muscle strength [30].

Every muscle group was measured three times, and the highest score was recorded.

Reference values for muscle strength were obtained from a study of healthy Dutch children [31].

\section{Statistical analysis}

Statistical analyses were performed with the use of the Statistical Package for the Social Sciences for Windows (ver. 13.0; SPSS, Chicago, IL). Prediction percentages were calculated using the score of each individual patient divided by the mean of the reference values for age and gender. Differences in 6MWT performance between children with ESRD and reference values was made using the MannWhitney Rank Sum Test. Differences in anthropometric variables, aerobic capacity, muscle strength and blood pressure between children with ESRD and reference values were made using independent samples $t$ test.

The relationship between 6MWT performance and the following independent variables height, weight, BMI, haematocrit, hemoglobin, disease duration, muscle strength, VT and $\mathrm{VO}_{2 \text { peak }}$ was made using univariate Pearson correlations and multiple backward linear regression analysis.

Independent variables that showed a significant univariate relationship $(p<0.05)$ with the dependent variables (\% of predicted 6MWT performance according to the reference values of $\mathrm{Li}$ et al. [20] or Geiger et al. [19]) were entered in the final multiple linear regression model in which variables with $p>0.05$ were excluded by means of the backward procedure. The $\alpha$-level was set at $p<0.05$ for all analyses.

\section{Results}

Twenty children (13 boys, seven girls; mean age \pm SD $14.1 \pm$ 3.4 years) were enrolled in the study. Anthropometrics and clinical characteristics are illustrated in Table 2. Their mean body fat percentage was $16.4 \pm 7.58 \%$ (range 5-31.1\%). Compared with the reference values, children with ESRD had a significantly lower mean $\mathrm{Z}$ score for height and a lower $\mathrm{Z}$ score.

In no case was it necessary to stop the tests prematurely, and there were no unexpected events during the tests. The 6MWT performance of the patients is shown in Table 3 and Fig. 1. Significantly reduced values were observed in the children with ESRD compared to the references values of Li et al. [20] $(p<0.0001)$ and Geiger et al. [19] $(p<0.0001)$. Both set of reference values gave percentages of predicted results and were highly correlated with each other $(R=0.975$, $p<0.0001)$. There was no significant difference in 6MWT performance between the patients on haemodialysis and those on peritoneal dialysis $(p=0.7)$.

The mean $\mathrm{HR}_{\text {peak }}$ was $168.67 \pm 22.78$ (range 131-201) beats/min during the progressive exercise test, which was significantly lower than the reference values $(p<0.001)$. Ten children did not meet the HR $>180$ criterium. The $\mathrm{RER}_{\text {peak }}$ was $1.15 \pm 0.15$ (range $0.94-1.44$ ), which was not significantly different from that of healthy subjects. Two children did not meet the RER $>1.0$ criterium. One child did not meet both $\mathrm{HR}_{\text {peak }}$ and $\mathrm{RER}_{\text {peak }}$ criteria. The $\mathrm{VO}_{2 \text { peak }} / \mathrm{kg}$ of the patients was $30.9 \pm 7.0$ (range 19.0$43.0) \mathrm{ml} / \mathrm{kg}$ per minute, which is $66 \pm 12 \%$ of the predicted value $(p<0.0001)$. Seventeen patients had a $\mathrm{VO}_{2 \text { peak }} / \mathrm{kg}$ lower than $-2 \mathrm{SD}$. The $\mathrm{W}_{\text {peak }}$ was $113.02 \pm 48.1$ (range $42.5-220) \mathrm{W}$, which is $54.4 \pm 17 \%$ of the predicted $(p<$ 0.0001 ). Only three patients had a $\mathrm{W}_{\text {peak }}$ higher than -2 SD. The VT appeared at $32.7 \pm 8.9 \%(21.3-51.3 \%)$ of the predicted $\mathrm{VO}_{2 \text { peak }}$, which is $55 \pm 15 \%$ of the predicted compared to healthy subjects.

Muscle strength was, on average, $73 \pm 29(p<0.001), 60 \pm 16$ $(p<0.0001), 62 \pm 15(p<0.0001), 91 \pm 25(p=0.49)$ and $62 \pm$ $16 \%(p<0.0001)$ of that predicted for grip strength, knee flexion, knee extension, foot dorsal flexion and hip flexion, respectively. Of the total study population $(n=20), 8,11,6,2$ and 8 patients had a muscle strength lower than -2 SD for grip strength, knee flexion, knee extension, foot dorsal flexion and hip flexion respectively.

Correlation analysis for height, weight, BMI, haematocrit, hemoglobin, muscle strength and aerobic fitness showed that only height, haematocrit, hemoglobin and VT were significantly associated with $6 \mathrm{MWD}$ when considered as a percentage of the reference values obtained by Li et al. [20] and Geiger et al. [19]. Six-minute walking performance was not associated with the use of antihypertensive medications, growth hormone and recombinant erythropoietin. 
Table 2 Clinical characteristics of the study cohort

\begin{tabular}{lll}
\hline Variables & Mean \pm SD (range) & Z scores \pm SD \\
\hline Height $(\mathrm{m})$ & $1.48 \pm 0.20(1.10-1.85)$ & $-2.0 \pm 1.4$ \\
Weight $(\mathrm{kg})$ & $44.6 \pm 18.1(19.5-81.0)$ & $-0.83 \pm 1.5$ \\
Body mass index $\left(\mathrm{kg} / \mathrm{m}^{2}\right)$ & $19.4 \pm 4.2(15.0-31.0)$ & $0.58 \pm 2.0$ \\
$\sum$ 4SF $(\mathrm{mm})$ & $36.2 \pm 17.9(15.0-71.6)$ & $0.40 \pm 2.0$ \\
Hemoglobin $(\mathrm{mmol} / \mathrm{l})$ & $7.4 \pm 1.0(5.3-8.4)$ & - \\
Haematocrit $(1 / \mathrm{l})$ & $0.35 \pm 0.04(0.25-0.42)$ & - \\
Systolic blood pressure $(\mathrm{mmHg})$ & $122.2 \pm 18(93-149)$ & $1.4 \pm 1.7$ \\
Diastolic blood pressure $(\mathrm{mmHg})$ & $76.1 \pm 10.2(63-101)$ & $1.2 \pm 0.9$ \\
\hline
\end{tabular}

Height, haematocrit and VT were entered in the backward regression analysis (Table 4). Because haematocrit and haemoglobin were strongly correlated $(r=0.955, p<0.0001)$, only haematocrit was entered in the regression analysis because it had slightly higher correlation coefficients with 6MWT performance compared to haemoglobin (\% predicted according to Geiger et al.: $r=0.707$ vs. $r=0.772 ; \%$ predicted according to $\mathrm{Li}$ et al.: $r=0.651$ vs. $r=0.717$, respectively).

Height and haematocrit were significant predictors of 6MWD performance using the $\mathrm{Li}$ et al. [20] reference values, while haematocrit was the only significant predictor of 6MWD performance using the Geiger et al. [19] reference values. Both models predicted approximately $60 \%$ of the variance in $6 \mathrm{MWT}$ performance.

\section{Discussion}

The aim of the study reported here was to investigate the $6 \mathrm{MWT}$ performance of children with ESRD compared to reference values obtained in healthy children (discrimination validity) and, secondly, to study the relationship between 6MWT performance and anthropometric variables, clinical variables, aerobic fitness and muscle strength (construct validity).

We found that the 6MWT performance of the children with ESRD participating in our study was significantly

Table 3 Results of the six-minute walking test in children with end stage renal disease

\begin{tabular}{lll}
\hline 6MWT & Mean \pm SD & Range \\
\hline 6MWT-Distance (m) & $554.6 \pm 90.4$ & $420-739$ \\
Predicted 6MWD-Li (m) & $666.85 \pm 30.9$ & $610-725$ \\
Predicted 6MWD-Geiger (m) & $663.26 \pm 37.75$ & $595-726$ \\
\% predicted-Li & $83.4 \% \pm 11.04$ & $68-109$ \\
$\%$ predicted-Geiger & $83.3 \% \pm 10.8$ & $69-108$
\end{tabular}

6MWD, 6-Minute walking test-distance; \% predicted-Li, 6MWD as a percentage of the reference values obtained from Li et al. [20]; \% predicted-Geiger, 6MWD as a percentage of the reference values obtained from Geiger et al. [19] lower than the reference values of Li et al. [20] and Geiger et al. [19], but they were comparable to those reported recently by Goldstein and Montgomery, who found a mean 6MWT distance of $538 \mathrm{~m}$ [4] in ten children receiving haemodialysis. Compared to other children with a chronic disease, our children with ESRD performed better that those with JIA (approx.72\% of predicted) and ambulatory children with spina bifida (approx. 60\% of predicted), but they performed worse than those with haemophilia $(90 \%$ of predicted) [9]. We are also able to confirm the previous finding of Hassan et al. [9] that the reference values of Li et al. [20] and Geiger et al. [19] are comparable when used in children with a chronic disease. There are, however, slight differences in the performance parameters of the 6MWT between these two studies. For example, Geiger et al. [19] used a measuring wheel as an incentive device during the test and a 20-m track, while Li et al. used a 30.5-m track. These differences do not seem to matter in terms of the applicability of the reference values.

The strongest predictors for 6MWT performance in our study were haematocrit and height. Height is not surprising since it is known from work with healthy children that height is a strong prediction of 6MWT performance. Consequently, both reference values are based on height

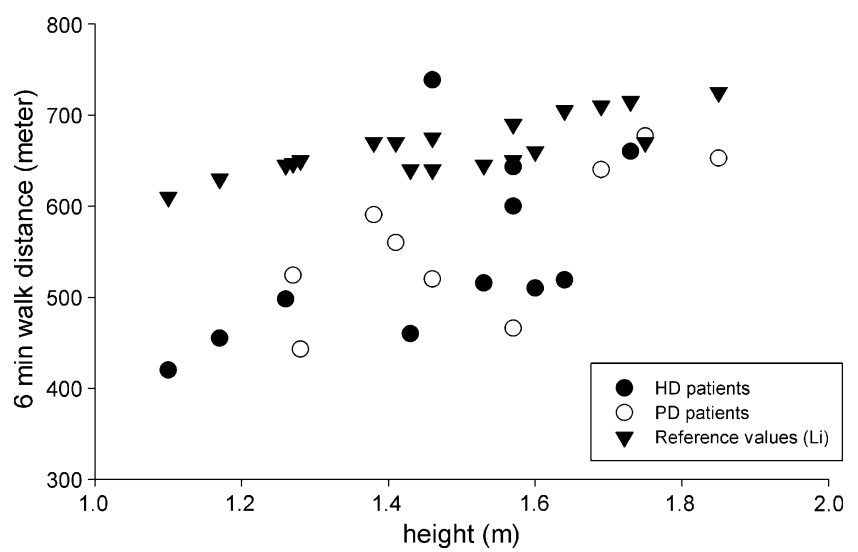

Fig. 1 The six-minute walking performance of children with end stage renal disease ESRD and healthy children (reference values according to $\mathrm{Li}$ et al. [20]) in relation to height. $H D$ haemodialysis, $P D$ peritoneal dialysis 
Table 4 Regression models of 6MWD as a percentage of the reference values according to $\mathrm{Li}$ et al. [20] and Geiger et al. [19]

\begin{tabular}{|c|c|c|c|c|c|}
\hline \multirow[t]{2}{*}{ Variable } & \multicolumn{2}{|c|}{ Li et al. [20] } & & \multicolumn{2}{|c|}{ Geiger et al. [19] } \\
\hline & $\begin{array}{l}\text { B } \\
\text { coefficient }\end{array}$ & $\begin{array}{l}95 \% \\
\text { CI }\end{array}$ & & $\begin{array}{l}\text { B } \\
\text { coefficient }\end{array}$ & $\begin{array}{l}95 \% \\
\mathrm{CI}\end{array}$ \\
\hline Constant & 0.056 & $\begin{array}{r}-0.283- \\
0.395\end{array}$ & & 0.177 & $\begin{array}{r}-0.93- \\
0.447\end{array}$ \\
\hline $\begin{array}{l}\text { Haematocrit } \\
(\%)\end{array}$ & -0.06 & $\begin{array}{r}0.611- \\
2.376\end{array}$ & & 1.886 & $\begin{array}{r}1.116- \\
2.655\end{array}$ \\
\hline Height (m) & 0.17 & $\begin{array}{r}-0.022- \\
0.363\end{array}$ & & & \\
\hline R2 & & & 0.59 & & \\
\hline
\end{tabular}

B, Regression coefficient; CI, confidence interval

(Li et al. [20]) or age and height (Geiger et al. [19]). In an earlier study in children with JIA, we also found that height was a significant predictor of 6-min walking distance [22]. A greater height will result in a larger leg length and hence a larger step length and walking speed.

Haematocrit was a strong predictor of 6MWT performance as well. This was surprising as haematocrit was not related to $\mathrm{V} \mathrm{O}_{2 \text { peak }} \mathrm{W}_{\text {max }}$ or muscle strength in our patients. However, a previous study in anaemic adult patients who were receiving haemodialysis, found that $6 \mathrm{MWT}$ distance increased with increasing haemoglobin concentration (correlation not reported) [32]. Moreover, increased exercise capacity $\left(\mathrm{V}_{2 \text { peak }}\right)$ has been reported in adult and paediatric dialysis patients during their treatment of anaemia using erythropoietin [33, 34], although the $\mathrm{VO}_{2 \text { peak }}$ response to increasing haematocrit in dialysis patients was clearly blunted compared to healthy subjects [35]. Based on this strong association with haematocrit, the 6MWT may be an interesting clinical outcome instrument in children with ESRD.

Surprisingly, 6MWT performance was not significantly related to lower extremity muscle strength, grip strength, $\mathrm{V} \mathrm{O}_{\text {2peak }}, \mathrm{W}_{\text {peak }}$ or VT. Previous studies in children with $\mathrm{CF}$ [12] and cardiorespiratory disease [11] reported significant associations between 6MWT performance and $\mathrm{V} \mathrm{O}_{2 \text { peak }} / \mathrm{kg}$ or $\mathrm{W}_{\text {peak }}$. A study in children with JIA, however, reported no significant associations between 6MWT performance and $\mathrm{V} \mathrm{O}_{2 \text { peak }} / \mathrm{kg}$ or $\mathrm{W}_{\text {peak }}$ [13]. None of these studies reported on the relationship of BMWT performance and VT.

The children with ESRD in our study had a $\mathrm{V} \mathrm{O}_{2 \text { peak }} / \mathrm{kg}$ of $31.3 \pm 7.0$ (range 19-43) $\mathrm{ml} / \mathrm{kg}$ per minute. Our patients performed worse than those with $\mathrm{CF}$, as reported in the study

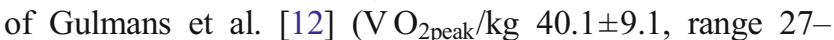
$60 \mathrm{ml} / \mathrm{kg}$ per minute), but better than the children with cardiopulmonary conditions in the study of Nixon et al. [11] $\left(\mathrm{VO}_{2 \text { peak }} / \mathrm{kg} 19.0 \pm 5.1\right.$, range $9.5-26.6 \mathrm{ml} / \mathrm{kg}$ per minute). This difference is not surprising as the patients in the latter study were candidates for lung and/or heart transplantations.
It is difficult to explain why the 6MWT performance was unrelated to $\mathrm{V} \mathrm{O}_{2 \text { peak }}$. Children with ESRD may have a different sensation of their perceived exertion during exercise because of abnormalities in their muscle metabolism [2]. As such, they may select a walking intensity based on oxygen delivery and/or a sensation of fatigue, which is unrelated to $\mathrm{VO}_{2 \text { peak }}$ but which may be restricted by limitations in the skeletal muscle to extract oxygen [35].

Based on the significantly reduced values for aerobic fitness and muscle strength that we found in our study, a training programme may be indicated for children with ESRD. However, two recent pilot-studies have encountered significant challenges in patient adherence during such exercise training programmes $[3,4]$. Based on the findings of Goldstein and Montgomery, the 6MWT seems to be a sensitive instrument for recording performance improvement as a result of exercise training in children with ESRD [4]. Moreover, based on it's strong association with haematocrit, it may be an interesting clinical outcome measure for monitoring the clinical status (e.g. anaemia) of children with ESRD. However, more research is needed in this area.

Future studies using the 6MWT in children with ESRD should also determine the physiological strain of this test (i.e. heart rate, oxygen uptake etc) as well as the reproducibility of the test.

One limitation of this study is a possible selection bias. Patients who participate in exercise studies may be more interested in physical activity and may have a relatively higher exercise capacity than those who do not. It is known from the literature that self-selected subjects for an exercise test have a $5-10 \%$ higher fitness level than a randomly selected population [36]. In fact, the result may be somewhat worse in an average population of children with ESRD. Waever et al. [37] observed a $\mathrm{VO}_{2 \text { peak }} / \mathrm{kg}$ of approximately $25 \mathrm{ml} / \mathrm{kg}$ per minute in 12 children with ESRD on haemodialysis, and Painter et al. [2] reported a mean $\mathrm{V} \mathrm{O}_{2 \text { peak }} / \mathrm{kg}$ of $27.9 \mathrm{ml} / \mathrm{kg}$ per minute in 15 children who underwent haemodialysis or peritoneal dialysis. Our patients scored, on average, a somewhat higher $\mathrm{V} \mathrm{O}_{2 \text { peak }} / \mathrm{kg}$ ( $31.3 \mathrm{ml} / \mathrm{kg}$ per minute). This difference may be caused by a higher body mass in the patients of the other studies [2, 37], as increased body mass is probably due to a higher body fat percentage. Painter et al. [2] reported a mean body fat percentage of $26.9 \%$, which is quite a lot higher that the percentage body fat in our subjects (16.4\%).

In conclusion, we found that children with ESRD performed significantly poorer on the 6MWT in comparison with reference values and that their performance was significantly associated with haematocrit and height. The two sets of reference values used here provided similar results. The 6MWT may be a useful instrument for monitoring clinical status in children with ESRD, however it cannot 
substitute for other fitness tests, such as a progressive exercise test to measure $\mathrm{V} \mathrm{O}_{2 \text { peak }}$ or a muscle strength test.

Acknowledgements This study was supported by the Nierstichting Nederland (Dutch Kidney Foundation) (grant nr. KI30). We thank all of the children and their parents who participated in this study.

Open Access This article is distributed under the terms of the Creative Commons Attribution Noncommercial License which permits any noncommercial use, distribution, and reproduction in any medium, provided the original author(s) and source are credited.

\section{References}

1. Bar-Or O, Rowland TW (2004) Pediatric exercise medicine. From physiologic principles to healthcare application. Human Kinetics, Champaign, IL

2. Painter P, Krasnoff J, Mathias R (2007) Exercise capacity and physical fitness in pediatric dialysis and kidney transplant patients. Pediatr Nephrol 22:1030-1039

3. van Bergen M, Takken T, Engelbert R, Groothoff J, Nauta J, van Hoeck K, Helders P, Lilien M (2009) Exercise training in pediatric patients with end-stage renal disease. Pediatr Nephrol 24:619-622

4. Goldstein SL, Montgomery LR (2009) A pilot study of twiceweekly exercise during hemodialysis in children. Pediatr Nephrol 24:833-839

5. Johansen KL (2008) Exercise and dialysis. Hemodial Int 12:290 300

6. Fitts SS, Guthrie MR (1995) Six-minute walk by people with chronic renal failure. Assessment of effort by perceived exertion. Am J Phys Med Rehabil 74:54-58

7. Solway S, Brooks D, Lacasse Y, Thomas S (2001) A qualitative systematic overview of the measurement properties of functional walk tests used in the cardiorespiratory domain. Chest 119:256-270

8. Schoenmakers MA, de Groot JF, Gorter JW, Hillaert JL, Helders PJ, Takken T (2009) Muscle strength, aerobic capacity and physical activity in independent ambulating children with lumbosacral spina bifida. Disabil Rehabil 104:657-665

9. Hassan J, van der Net J, Helders PJ, Prakken BJ, Takken T (2008) Six-minute walk test in children with chronic conditions. $\mathrm{Br} \mathrm{J}$ Sports Med. doi:10.1136/bjsm.2008.048512

10. Moalla W, Gauthier R, Maingourd Y, Ahmaidi S (2005) Sixminute walking test to assess exercise tolerance and cardiorespiratory responses during training program in children with congenital heart disease. Int J Sports Med 26:756-762

11. Nixon PA, Joswiak ML, Fricker FJ (1996) A six-minute walk test for assessing exercise tolerance in severely ill children. J Pediatr 129:362-366

12. Gulmans VA, van Veldhoven NH, de Meer K, Helders PJ (1996) The six-minute walking test in children with cystic fibrosis: reliability and validity. Pediatr Pulmonol 22:85-89

13. Lelieveld OT, Takken T, van der Net J, van Weert E (2005) Validity of the 6-minute walking test in juvenile idiopathic arthritis. Arthritis Rheum 53:304-307

14. Li AM, Yin J, Yu CCW, Tsang T, So HK, Wong E, Chan D, Hon EKL, Sung R (2005) The six-minute walk test in healthy children: Reliability and validity. Eur Respir J 25:1057-1060

15. Cunha MT, Rozov T, de Oliveira RC, Jardim JR (2006) Sixminute walk test in children and adolescents with cystic fibrosis. Pediatr Pulmonol 41:618-622

16. Humpl T, Reyes JT, Holtby H, Stephens D, Adatia I (2005) Beneficial effect of oral sildenafil therapy on childhood pulmonary arterial hypertension: Twelve-month clinical trial of a single-drug, open-label, pilot study. Circulation 111:3274 3280

17. Takken T, van der Net J, Helders PJ (2001) Do juvenile idiopathic arthritis patients benefit from an exercise program? A pilot study. Arthritis Rheum 45:81-85

18. Lammers AE, Hislop AA, Flynn Y, Haworth SG (2008) The 6minute walk test: normal values for children of 4-11 years of age. Arch Dis Child 93:464-468

19. Geiger R, Strasak A, Treml B, Gasser K, Kleinsasser A, Fischer V, Geiger H, Loeckinger A, Stein JI (2007) Six-minute walk test in children and adolescents. J Pediatr 150:395-399

20. Li AM, Yin J, Au JT, So HK, Tsang T, Wong E, Fok TF, Ng PC (2007) Standard reference for the 6-minute walk test in healthy children aged 7 to 16 years. Am J Respir Crit Care Med 176:174-180

21. ATS Committee on Proficiency Standards for Clinical Pulmonary Function Laboratories (2002) ATS statement: guidelines for the six-minute walk test. Am J Respir Crit Care Med 166:111-117

22. Paap E, van der Net J, Helders PJ, Takken T (2005) Physiologic response of the six-minute walk test in children with juvenile idiopathic arthritis. Arthritis Rheum 53:351-356

23. Latin RW (1998) Surface anatomy. In: Roitman JL (ed) ACSM's resource manual for guidelines for exercise testing and prescription. Williams and Wilkins, Baltimore, pp 89-100

24. Durnin JV, Rahaman MM (1967) The assessment of the amount of fat in the human body from measurements of skinfold thickness. Br J Nutr 21:681-689

25. Gerver WJM, De Bruin R (2001) Paediatric morphometrics. Universitaire Pers Maastricht, Maastricht

26. National High Blood Pressure Education Program Working Group on High Blood Pressure in Children and Adolescents (2004) The fourth report on the diagnosis evaluation and treatment of high blood pressure in children and adolescents. Pediatrics 114:555-576

27. Godfrey S (1974) Exercise testing in children. W.B. Saunders, London

28. Caiozzo VJ, Davis JA, Ellis JF, Azus JL, Vandagriff R, Prietto CA, McMaster WC (1982) A comparison of gas exchange indices used to detect the anaerobic threshold. J Appl Physiol 53:1184-1189

29. Binkhorst RA, van't Hof MA, Saris WHM (1992) Maximal exercise in children; reference values girls and boys, 6-18 year of age. Nederlandse Hartstichting, Den Haag

30. Wind AE, Takken T, Helders PJ, Engelbert RH (2009) Is grip strength a predictor for total muscle strength in healthy children, adolescents, and young adults? Eur J Pediatr. doi:10.1007/s00431009-1010-4

31. Beenakker EA, van der Hoeven JH, Fock JM, Maurits NM (2001) Reference values of maximum isometric muscle force obtained in 270 children aged $4-16$ years by hand-held dynamometry. Neuromuscul Disord 11:441-446

32. Canadian Erythropoietin Study Group (1990) Association between recombinant human erythropoietin and quality of life and exercise capacity of patients receiving haemodialysis. BMJ 300:573-578

33. Robertson HT, Haley NR, Guthrie M, Cardenas D, Eschbach JW, Adamson JW (1990) Recombinant erythropoietin improves exercise capacity in anemic hemodialysis patients. Am J Kidney Dis 15:325-332

34. Warady BA, Sabath RJ, Smith CA, Alon U, Hellerstein S (1991) Recombinant human erythropoietin therapy in pediatric patients receiving long-term peritoneal dialysis. Pediatr Nephrol 5:718-723

35. Painter P (2008) Exercise in chronic disease: Physiological research needed. Exerc Sport Sci Rev 36:83-90

36. Mitchell JH, Saltin B (2003) The oxygen transport system and maximal oxygen uptake. In: Tipton CM (ed) Exercise physiology people and ideas. Oxford University Press, Oxford, pp 255-291

37. Weaver DJ Jr, Kimball TR, Knilans T, Mays W, Knecht SK, Gerdes YM, Witt S, Glascock BJ, Kartal J, Khoury P, Mitsnefes MM (2008) Decreased maximal aerobic capacity in pediatric chronic kidney disease. J Am Soc Nephrol 19:624-630 